\title{
Eco-Efficiency Analysis for Hydraulic and Hybrid Concepts for Mobile Working Machines
}

\author{
C. Schindler ${ }^{1}$, M. Eigner ${ }^{2}$, C. Scholler ${ }^{1}$, and P. Schaefer ${ }^{2}$ \\ ${ }^{1}$ Chair of Design in Mechanical Engineering, University of Kaiserslautern, Kaiserslautern, Germany \\ ${ }^{2}$ Institute for Virtual Product Engineering, University of Kaiserslautern, Kaiserslautern, Germany \\ E-mail: schindler@mv.uni-kl.de, eigner@mv.uni-kl.de, scholler@mv.uni-kl.de, schaefer@mv.uni-kl.de
}

\begin{abstract}
The sector of construction equipment is currently in change. The scarcity of fossil resources and raw materials as well as rising energy costs in the last years and new political and technical requirements has brought the industry to a massive rethinking. A reduction of energy consumption is one of the most important innovation topics in this industry branch. In order to fulfill high energy requirements in the near future, extensive concepts, new structures and innovative technical approaches increasing the total energy efficiency of the product are needed. Therefore the importance of life cycle based eco-efficiency analysis must be considered. Life Cycle Assessment (LCA) and Eco-efficiency assessment are powerful tools for achieving design for life cycle. An LCA examines all stages of a product's life cycle and gives a quantitative assessment of its potential environmental impact. In addition, the results of an Ecoefficiency assessment help to identify priority areas for ecological improvement which are economically worthwhile. This paper presents a comprehensive approach integrating technical analyses to recognize and evaluate possible improvement areas within the machine's construction for doing a quantitative assessment of the environmental impact of the improved technical concepts. The paper describes how LCA and Eco-efficiency assessment can be applied for hydraulic and hybrid concepts and how it can be used to improve the environmental performance of a product in an early step of the life cycle. The approach is demonstrated on the example of a wheeled excavator.
\end{abstract}

Keywords: Hydraulic and Hybrid Optimization, Eco-Efficiency Assessment, Life Cycle Assessment, Product Lifecycle Management, Modular Based Simulation.

\section{Introduction}

The awareness of limited resources availability, environmental problems and pollution, the increasing demand for goods, energy and materials, as well as the increase of costs of scarce resources, all are calling for a new paradigm of life, overcoming the obsolete consumerist model of modern societies. The reduction of energy consumption and successive use of renewable energy are one of the most important innovation topics in the automotive industry. New and further developments for reducing fuel consumption and $\mathrm{CO}_{2}$ emissions can be seen mainly in the passenger cars sector, where political requirements on technical developments are already very high. In the field of construction equipment, with wellestablished hydraulic and hybrid systems, the further increase of energy costs, the need of sustainable production models and the growing competitive pressure will increase significantly because of energetic requirements, too. Therefore extensive concepts, new structures just as innovative and integrated technical approaches for increasing the total energy efficiency of construction equipment are needed [1][2]. This demand of high flexibility leads to complex systems which contain mechanic, hydraulic electric and even hybrid subsystems. The overall effect of energy and resource reduction of these new technical concepts is often hard to predict, especially within a life cycle view taken into account. Already promising technical concepts are in pre-commercial development, but their performance is frequently designed for the operation efficiency at a specific load scenario. Often, they are not tested within a total life cycle perspective. [3] This paper presents a comprehensive approach to estimate the life cycle based eco-efficiency for future hydraulic and hybrid concepts of construction equipment. The approach involves an implementation of Life Cycle Assessment (LCA) and Eco-efficiency assessment as fully integrated within the Product Lifecycle Management (PLM) supporting the engineering in terms of sharing relevant product data across modules and life cycle phases. The capabilities of the proactive Life Cycle Assessment and Eco-efficiency assessment solution for a sustainable management are examined and presented on the example of a wheeled excavator. 


\section{Sustainable Management}

Moreover, to be competitive on the global market in time of an increasing shortage of resources, companies have to develop not only good products but have to make them also more sustainable. Sustainable Development, conceptually founded on the three dimensions economical, ecological and social sustainability, is the main paradigm for future improvement of humankind in the $21^{\text {st }}$ century [4]. One of the guiding principles for engineering design is to develop products that conform to the sustainability paradigm [5]. In the discourse on sustainable management, the potential of the product development process is currently inadequately treated [6] [7]. A sustainable product development aims at the real goods, but also on the assessment of environmental, ecological and social issues over its entire life cycle. Therefore, a total approach is necessary, accompanying the product from the initial idea, through the development and manufacturing phases, the usage and all end-of life treatments. Already in the early phases of the life cycle, the engineer defines key properties of a product, implicitly including the definition of the resulting life cycle costs as well as environmental and social effects: The product shape is clearly determined by the product development [5]. A central problem for those companies interested in sustainable management is to analyze, to optimize and to communicate its product portfolio with as low as possible effort. Therefore the process of creating a more sustainable product needs to be monitored and managed from the very first beginning, whether a new product is to be designed or an existing one is to be improved [8]. This is also of importance for companies producing construction equipment [3] [8]. To address a sustainable product development or engineering design process, appropriate methods and tools are required. Internationally standardized tools for the assessment of environmental-economical sustainability of a product system do already exist - Life Cycle Assessment [9] and Eco-efficiency assessment [10].

\subsection{Regarding the Environmental Impact}

The ISO 14040 standardized Life Cycle Assessment (LCA) [9], as part of a sustainability assessment, provides a meaningful methodological framework for the ecological dimension [11]. The product related Life Cycle Assessment (LCA) with an emphasis on energy, resource and waste, first started back in the 1970s, in time of the famous report "The Limits to Growth`, addressed to the Club of Rome and the first worldwide oil crisis, which brought awareness of the finiteness of oil and revealed the vulnerability of the global economic system. In the 1990s LCA was developed as method, mainly driven by the Society of Environmental Toxicology and Chemistry (SETAC), and standardized by the International Organization for Standardization (ISO). Later on, in 2006 the international series of LCA standards have been slightly revised to their current version of ISO 14040 and ISO 14044 [12]. [13] The basic principles of any Life Cycle Assessment are the cradle-to-grave analysis and the use of functional unit. All mass and energy flows, resource and land use, and even the potential impacts and probable interventions are set in relation to the functional unit as quantitative measures of the benefit. Life Cycle Assessment is a method to analyze environmental parameters out of the environmental profile of a product system and across its life cycle. The environmental profile of a product system is thereby determined and dependence on five categories [14]:

- $\quad$ Energy use

- Material use

- Emissions in air, water and soil

- Toxic potential of used and released substances

- Compliance to environmental laws and regulations

Life Cycle Assessment can systematically identify key areas to improve environmental performance, even applied to the sector of construction equipment. The main characteristic of the standards ISO 14040 and ISO 14044 is the clear framework which consists in four components [9] [12]:

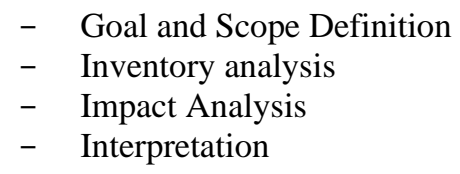

The definition of the goal and the scope of any LCA is crucial, since this is the phase of essential determinations. According to the aims and the insight interest, a survey framework is defined and demands on further phases are determined. This may concern the intensity of a survey, the necessary quality of data, a selection of the effect parameters with regard to the impact assessment, and the interpretive possibilities within the framework of an evaluation. In the inventory analysis, all material and energy flows are grasped and listed during their entire life cycle. In a first step, process structures are modeled in order to have a basis for assembling data. All material and energy flows are determined as input-/output-sizes for every partial process with regard to the system boundary. By connecting all partial processes, the relations between the modules and the environment are represented, and the mass/energy balance is drawn up as the inventory of the total system. All material and energy streams which pass the system borders are listed as quantities in physical units. The data refer to the functional unit. The task of the impact assessment is the evaluation of all material and energy flows raised in the inventory analysis according to certain environmental effects. Thus, an impact assessment serves the recognition, summarization, and quantification of the potential environmental effects of the examined systems and delivers essential information for the evaluation. [13] The following impact categories are usually included into a LCA [15]:

- Global warming Potential (GWP)

- Stratospheric ozone depletion (ODP)

- Tropospheric photochemical ozone creation (POCP)

- Acidification (AP)

- Eutrophication (NP)

- Human toxicity (HTP)

- Ecotoxicity (ETP) and

- Land use 
The impact categories describe potential effects on human and environment. Among other things, they differ according to their spatial references (global, regional and local effects). In principle, every environmental effect can be included into the survey, as long as the necessary data and a suitable model for the description and parameterization of the effect are available. The task of the interpretation step is the analysis of the results as well as the explanation of the meaningfulness and the restrictions. The essential facts, based on the results of the inventory analysis and the impact assessment, are to be determined and checked with regard to their completeness, sensitivity, and consistency of the results. The assumptions made in the phase of the goal and scope definition have to be considered. Based on this, conclusions have to be drawn and recommendations are to be made. [13] The Life Cycle Assessment is an essential comparative method to estimate the environmental aspects of a product system. It explores environmental performance and potential environmental impacts across the product life cycle, from raw material extraction, across production, to reuse of recyclates and waste disposal. A LCA can assist engineers and decision-makers in industry by identifying opportunities to improve the environmental performance of product systems and providing them with a platform for observing the environmental product declarations and environmental compliance, thus support the design of more eco-efficient products.

\subsection{From LCA to Eco-Efficiency Assessment}

A first step towards an integrated sustainability assessment provides the link between economic and ecological issues and is represented in the international standard ISO 14045 Eco-efficiency assessment of product systems: principles, requirements and guidelines, adopted in 2012 [10]. The principles relate to the ISO 14040 - 14044 for product systems, and are translated into specific objectives [16]:

- Minimize energy intensity

- Minimize material intensity of goods and services

- Maximize the use of renewable resources

- Minimize toxic dispersion

- Extend product durability

- Increase product efficiency

- Promote recycling

The objective of an Eco-efficiency assessment is to support the economical-ecological evaluation of different product systems by providing an overall life cycle view.

\subsection{Beyond an Eco-Assessment}

To arrange an LCA or an Eco-efficiency assessment, it is a very complex, time-intensive and cost-intensive task. This is based on the fact that an extensive data base of a product system with its processes is needed [17][18]. The practice of the standards ISO 14040-14044 and ISO 14045 is, due to a high complexity, often carried out with special software tools [17][19]. It becomes apparent that the analysis of an existing product system is retrospective. But especially for complex products, like for construction equipment, the application of Life Cycle Assessment and Eco-efficiency in product development is very interesting [20]. The product development determines all other phases in life cycle, like the manufacturing, the usage and the end-of-life [21] [22]. Decisions in this early phase play a key role in terms of economic-ecological product design. According to [29] up to $70 \%$ of the total cost of ownership is set in the early phase of product development. In the same extent according [23] the environmental impacts of the final product system are determined. With a proactive Life Cycle Assessment and Eco-efficiency solution, a company can identify priority areas for improvement and become preemptive in its sustainability initiatives. This was the trigger for the research project ERMA underlying the following case study.

\section{Improving the Environmental Performance of Construction Equipment}

In order to fulfill the pressing problems of a sustainable management within the product development of construction equipment, four institutes at University of Kaiserslautern initiated the research project 'Energy and Resource Efficient Mobile Working Machines (ERMA). [3] Main objectives are the further development and application of methods and tools to estimate and evaluate the overall eco-efficiency of a wheeled excavator [20][24][25][26][27]. The advancement of new concepts for less energy and resource using subsystems is directed to improve the chosen product system with this consideration.

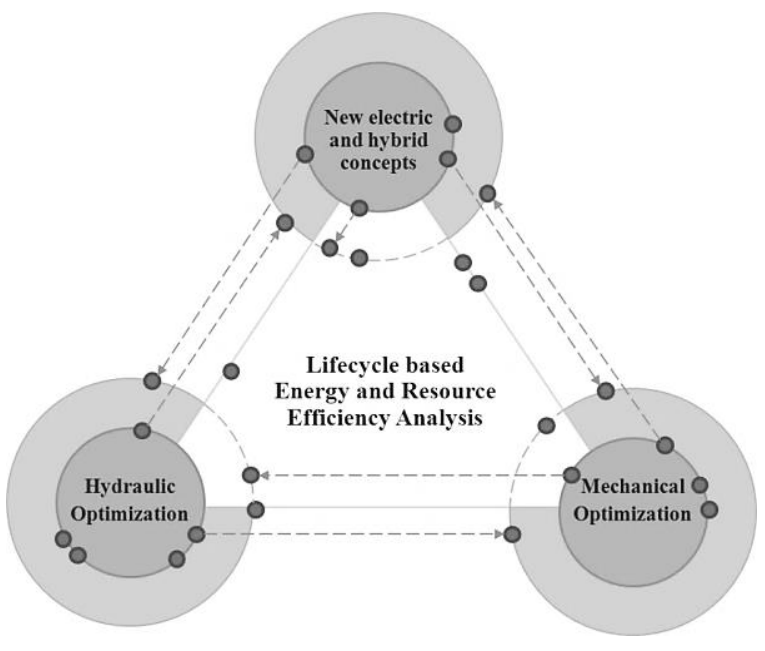

Figure 1: Interdisciplinary Optimization Supported
by Life Cycle Based Eco-Efficiency Analysis
(adapted from [3]).

In the first step, a modular simulation model of the wheeled excavator is created, followed by a verification of the full simulation model. The focus of the model is to calculate the energy consumption for specific load cycles, which can also be configured to specific customer usage profiles. Because of this, modular subsystems can easily be implemented in the model. This way the overall energy consumption of an improved technical system can be estimated as well. In a second step, the objective is to improve the current product system itself with respect to energy savings. Starting with the analysis and the minimization of friction losses of the 
existing bearings and seals, more efficient hydraulic solutions are developed. New concepts of electric or hybrid subsystems will be developed and introduced to substitute parts of the current hydraulic system for reducing the energy consumption. Same time, new methods and a concept for an integrated product life cycle based proactive eco-efficiency assessment are developed, and will be tested and verified. The project structure is shown in Figure 1. The interdisciplinary tasks within ERMA cover both: the technical improvements of construction equipment and an eco-analysis of the improved concepts. Therefore the results of the technical evaluations are used in the eco-efficiency analysis to get an overall result of single concepts including customer usage profiles for specific life cycles.

\subsection{Technical Evaluation}

The technical evaluation of ERMA aims to estimate the energy consumption and the system behavior of concepts during operation. With this, different concepts are comparable concerning for example the reliability of the concept, the operability of the machine as well as variable costs due to fuel consumption. For the evaluation process many influences have to be considered like proper reference data or the customer usage profile. Due to cost reduction a simulation model was used to estimate the energy consumption. The excavator was modeled along the common V-Model [28]: The hydraulic structure was reproduced in the numeric Simulation tool AMESim and with the help of measurement data and data sheets, the important parameters were defined and valued. The verification and validation process confirms the correctness of the model (see Figure 2). After that, an overall model of the excavator in its current state exists.

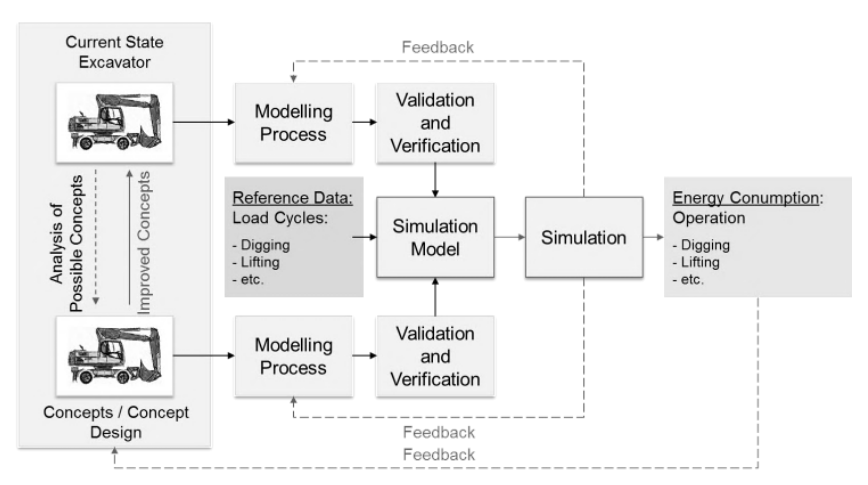

Figure 2: Technical Evaluation of new Hydraulic and Hybrid Concepts for a Wheeled Excavator.

If a new concept is modeled and implemented in the overall model, inevitably the model will change and a new model of the excavator comes into existence. If this is done with many concepts and maybe different parameter variations, the amount of different simulation models of the excavator will increase and the maintenance effort due to synchronization issues will rise exponentially. This will make it difficult to compare different technical concepts. To avoid that, a modular structure was implemented in the model. If the modules are suitable designed, it is possible to exchange only one or two modules to implement a new technical concept. With this, the overall structure of the simulation model is unchanged and no new simulation model will come into existence. Also the maintenance effort is restricted to the single modules. This approach was published in [27]. For the technical evaluation of a concept, a customer-usage-profile has to be defined. This is normally done by reducing the usage of the machine to a certain amount of load-cycles in combination with a weighting according to the amount of time a certain user operates the machine the specific load cycles [30][31]. But often, the usage of the machine is not known or differs from customer to customer. Hence, it is hardly possible to make an exact statement if a technical concept is eco-efficient or not related to its whole work cycle or even life cycle. For example, if a wheeled excavator is used for mass excavation, a regeneration device for the swing will generate a much better result as if the wheeled excavator is only used for driving or trench digging. Because of this issue, for ERMA we decided to expand the approach and take a variable user-profile into account. For that, the technical evaluation only considers different load-cycles without a weighting. The weighting will follow after the ecoefficiency analysis, see chapter 4 . This procedure has the advantage that the design of the machine is related to its purpose and a customer can get the ideal machine for his individual usage. In summary, the result of this approach calculates the unweighted energy consumption of concepts with respect to the defined load-cycles. With the modular structure of the simulation model, a comparison of the results between the single technical concepts is possible. The results will be forwarded to the product life cycle management solution, where they are used in the ecoefficiency analysis.

\subsection{Eco-Efficiency Analysis}

Complex products like construction equipment are characterized by a large number of constituent parts, complex processes and referring to the life cycle, high fuel consumption throughout a long life cycle [3][22]. Regarding the life cycle of a mobile working machine [8] or an agricultural machine [15] for example, an eco-efficiency analysis helps to identify environmental key factors and cost drivers within the use phase where $\mathrm{CO}_{2}$ emissions, resulting from fuel consumption, are very high. The operational ecoefficiency analysis of ERMA demonstrates how much environmental impact is caused by a product and its processes and how different life cycle phases as well as product subsystems contribute to the total impact [22]. The eco evaluation concept shown in Figure 3 is in addition to it closely linked to a product life cycle management solution. It extends the product model as well as the process model by technical-economical attention of ecological parameters, thus it allows an aggregated evaluation of energy and resource efficiency of the product system over the entire life cycle. Energetically improved technical products will assert themselves in enterprise practice only if they are advantageous in economic regard. Hence, the deliberate design of eco-efficient products is as important as both, economic balance and Life Cycle Assessment. The approach deals with this and is outlined in a way, that it corresponds 
to a multidimensional, interdisciplinary and federated life cycle management. Integrated funds on a solution that handles the whole life cycle of the product system, starting with a first idea up to the end-of-life. Federated calls for an engineering collaboration in distributed enterprises as well as within suppliers, customers or even the whole supply chain, and Multidisciplinary refers to the cooperation of different disciplines or specialized divisions which are involved in the product development. [22]

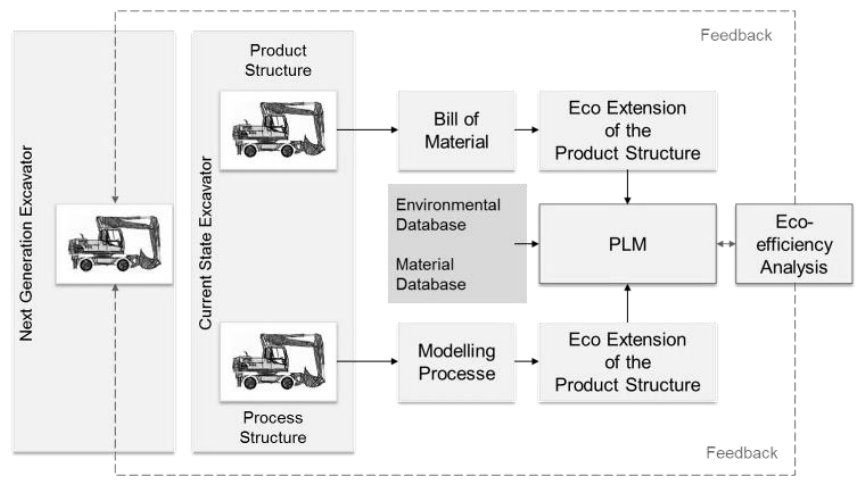

Figure 3: Eco Evaluation of new Technical Concepts for a Wheeled Excavator.

To achieve best practice, all concerned parties have to cooperate and tap into the know-how of all phases of a product life cycle. This leads to the need for an entire system solution.

\section{Comprehensive Approach}

The prospective view within ERMA requires the application of an eco-efficiency analysis in a proactive view for product development as well as an analysis which has to be applied to a complex system. This paper considers Product Lifecycle Management (PLM) [21] as one key concept for the establishment of sustainable engineering design processes. Product Lifecycle Management is based on the idea of connecting knowledge. It represents a concept rather than a monolithic IT-system. [31][32] PLM is an integrated, information-driven approach to improve the product performance over the entire life cycle. It achieves efficiency by using a shared information core system that helps business to efficiently manage complexity in the product life cycle from design to end-of-life. [21][31][33] Thus, PLM does not provide innovative products, but it is a concept that can contribute engineering at the administrative level by providing the right information at the right time in the right context [18]. As a consequence, Product Lifecycle Management can help to improve the environmental and sustainability performance of a product [34] [35] [36] [37].

\subsection{Identifying Priority Areas for Eco-Efficiency Improvements}

Regarding the material flow and the information flow on the entire life cycle, the most pertinent issues and important elements of an eco-efficient product strategy are highlighted (see Figure 4): As shown the relevant material flow consists of the three phases: manufacturing, usage and end-of-life treatment. Within the manufacturing, sub phases like extraction of raw material and the production of intermediate products as well as the entire product system are included. The usage includes the operation and maintenance, in our case, of a wheeled excavator. Here, fuel consumption and emissions from machine operation as well as the replacement of spare parts, filters, oils and fluids are all relevant targets and are taken into account. The end of life phase involves all recycling and disposal activities. [22]

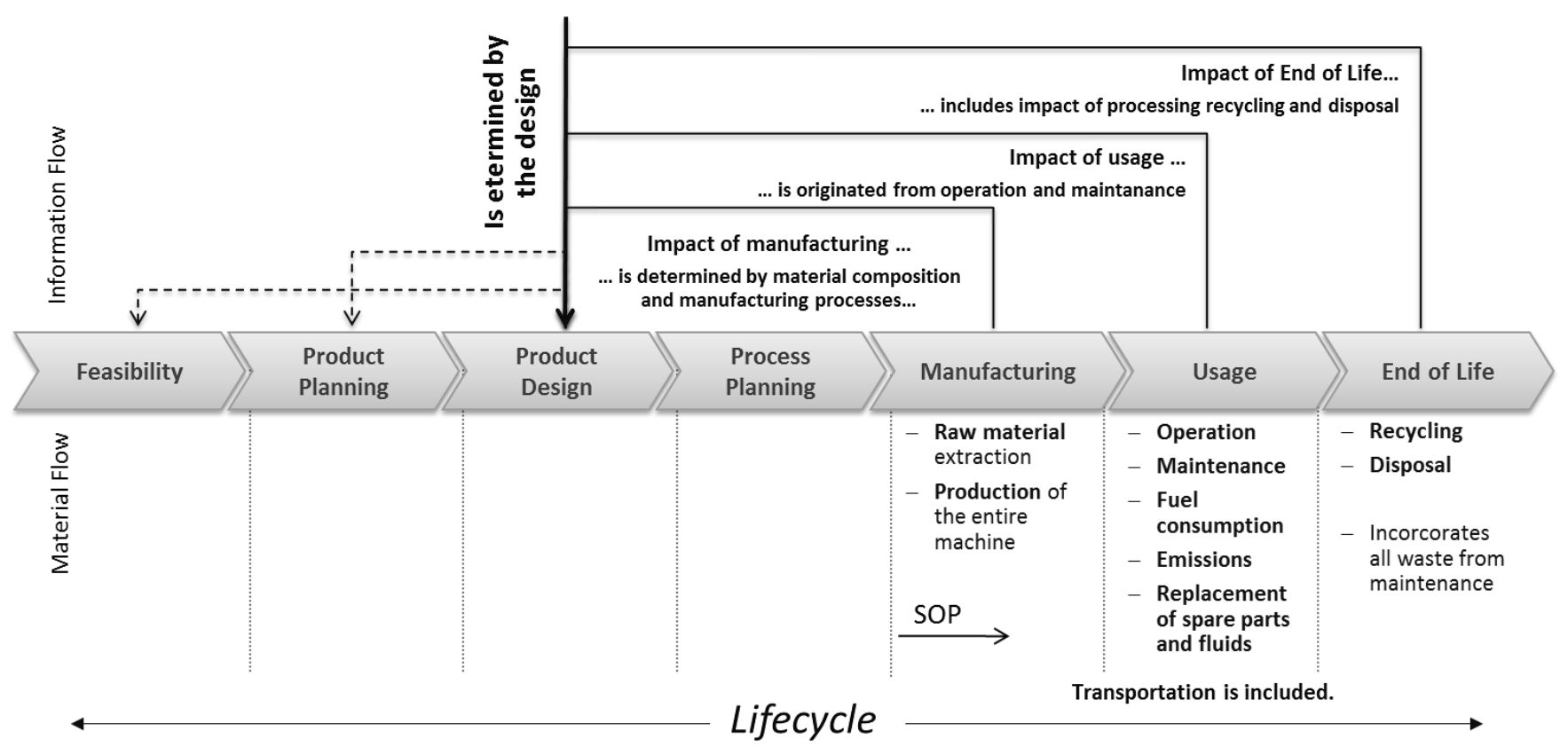

Figure 4: The Early Phase of the Product Development Takes a Key Role (adapted from [22]). 
As shown in the information flow, the impact of the manufacturing is determined by the design of the product system. It is defined by the composition of the assembly and sub-assembly, even so hydraulic, electric and hybrid components as well as their production processes and the production process of the entire product system, to be exact. Relevant sub-processes within the phases of manufacturing, usage an end-of-life, such as transportation are included. The impact of usage is originated as shown in Figure 4 from operation and maintenance. Main driver with the most impact on eco-efficiency does have the operation. New hydraulic and hybrid technical concepts will make a contribution and help to improve the impact of fuel consumption as well as the associated impact of emissions of the whole product system. [22] Even strategies to reduce the energy demand are an essential factor for future construction equipment. The increasing diversification of alternative technical concepts offers a great potential for electric and hybrid solutions and also further improved hydraulic solutions. [38] The impact of end-of-life treatment includes the impacts of processing the end-of-life product system and processing all replacement parts and fluids consumed over the lifetime of the wheeled excavator [22]. Even for construction equipment, regarding the cumulated energy demand of different used materials and in relation to their mass, it turns out that in future the use of recyclates will play an essential role [38]. The known information about the life cycle including material the flow, it applies making it available for new product design and improvements for current product. In order to address these potentials for engineering design, appropriate methods and tools are required. Several software solutions to assist decision-makers in the product development phase regarding the environmental impact do already exist. The selection exemplifies the degree of integration depth:

- GaBi Software

Stand-alone software solution LCA

at the product level.

- SimaPro Software

Stand-alone software solution LCA

at the product level.

- Sustainability Pro from Dassault Systèmes Software solution embedded into the $C A D$ of SolidWorks

- Teamcenter Sustainability and Environmental Compliance

Semi-integrated in PLM solution.

- Windchill Product Analytics

Stand-alone software solution

but in practice mainly semi-integrated in PLM solution.

It lacks to a fully integrated eco-efficiency solution into the Product Lifecycle Management. Below, the argument of how eco-efficiency analysis is integrated into Product Lifecycle Management is presented with a comprehensive approach for ERMA.

\subsection{A Concept of an Eco-Efficiency Analysis as Part of Product Lifecycle Management}

Within the research project ERMA, the existing Product Lifecycle Management solution is extended by enabling the monitoring of a product life cycle already in the early phases of an engineering design process. The total concept is shown in Figure 5. The objective of the eco-efficiency analysis is to support the evaluation of different optimized technical concepts by providing an overall life cycle view. The approach refers to Eco-efficiency assessment and is linked to the Product Lifecycle Management [34] [39]. It extends the product model as well as the process model by technicaleconomical attention of ecological parameters, thus it allows an aggregated evaluation of energy and resource efficiency of the product over the entire life cycle. Energetically improved technical products will assert themselves in enterprise practice only if they are advantageous in economic regard. Hence, the deliberate design of ecoefficiency products is as important as both economic balance and life-cycle assessment. The concept deals with both and is outlined in a way, that it corresponds to a multidimensional, interdisciplinary and federated lifecycle management. Aim of the analysis made with the Product Lifecycle Management solution is to measure multiple dimensions of the product performance in two of the three sustainability areas - ecological and economical. The modules share common, scalable infrastructure and support multiple methods for supplier data acquisition. Bidirectional integrations with multiple enterprise systems such as authoring systems and the PLM solution are also supported. The extended Product Lifecycle Management solution forecasts the eco-efficiency performance of the product system. Beside this, the solution audits the conformity to current environmental legislation. Just for the development of electric and hybrid solutions, this is of central importance. Environmental regulations influence companies to follow environmental procedures. They have to comply with governmental regulations or face immediate and serve consequences [33] [34]. The selection shows a summary of some current environmental legislation [18]:

$$
\begin{array}{ll}
- & \text { EuP } \\
& \text { Energy using Product } \\
- & \text { REACH } \\
& \text { Registration, Evaluation, and Authorization } \\
\text { of Chemicals } \\
-\quad \text { RoHS } \\
\text { Restriction of use of certain Hazardous Substances } \\
-\quad \text { WEEE } \\
\text { Waste Electrical and Electronic Equipment } \\
\text { ELV } \\
\text { End of Life Vehicle }
\end{array}
$$

To reach the goal, the design of eco-efficient construction equipment not only the need to choose materials that are compliant with regulations is necessary, but also the need to move beyond basic eco-compliance with a sustainability strategy that phases out or replaces current hydraulic components with new electric and hybrid ones. 


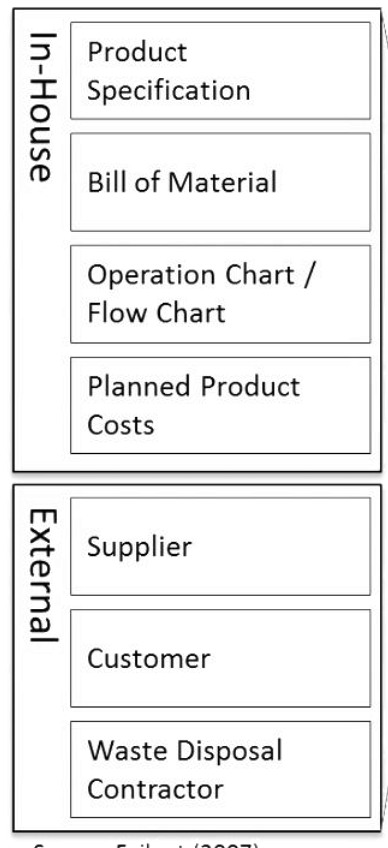

Source: Feikert (2007)
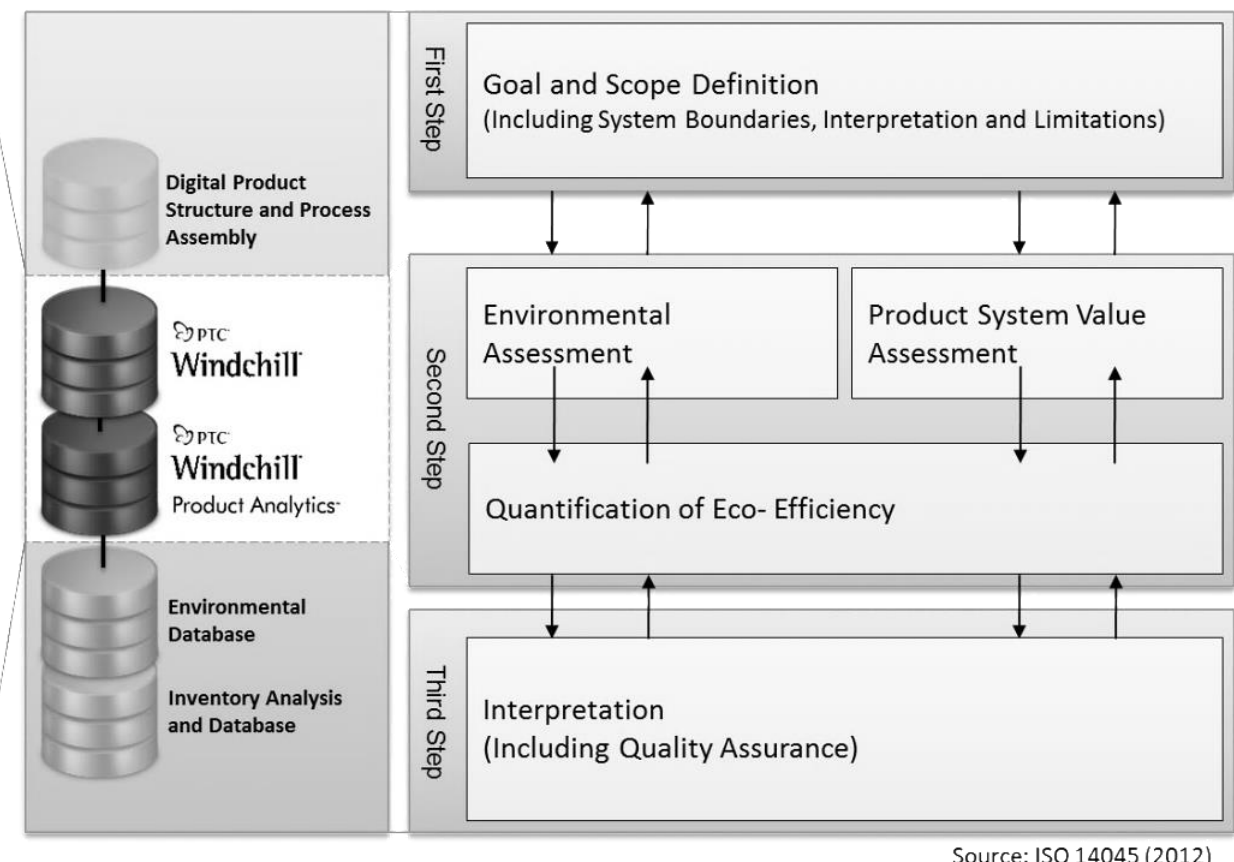

Figure 5: Concept of an Eco-Efficiency Analysis as Part of Product Lifecycle Management (adapted from [39])

The introduced Product Analytics module (see Figure 6) uses a streamlined Life Cycle Assessment approach for qualifying the environmental impact over the entire life cycle of a product. This means that relies primarily on secondary existing life cycle impact data from the wheeled excavator and, but not necessarily, third party data such as the ecoinvent eco-balance data base, to produce quick, relatively robust information. It has the capabilities to model and analyze embodied environmental impacts throughout the life cycle utilizing supplier material disclosures for that, it can identify highest impact areas among products, parts, material, suppliers as well as the choice of hydraulic and hybrid options. It provides relevant eco-efficiency data in report dashboards, which are of help for design engineers in the evaluation of improvement opportunities. [20]

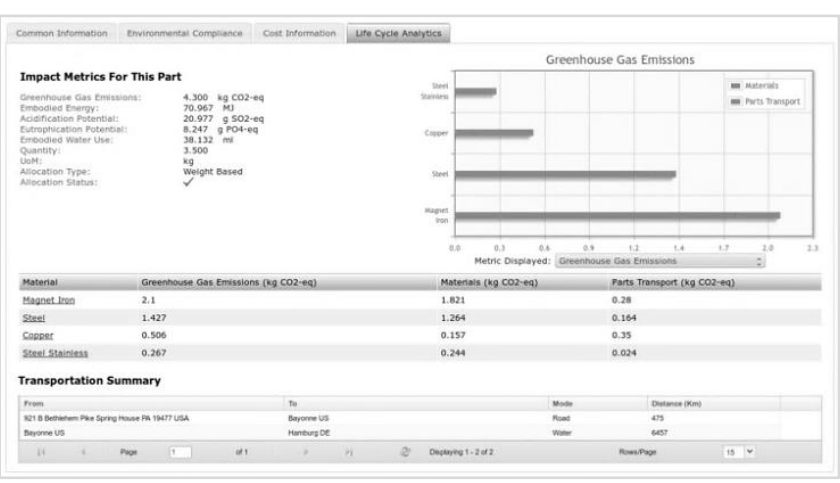

Figure 6: Life Cycle Analysis Dashboard of the Product Lifecycle Management Solution (adapted from [39])

The Environmental Compliance module (see Figure 7) is used to analyze and report compliance of company products or even chosen hydraulic and hybrid options of the intellectual product system to multiple standardized regulations and requirements such as EuP, REACH, RoHS, WEEE, and ELV using supplier material declarations as data source. It helps to measure and manage compliance risk early in the product development phase of next generation construction equipment. [20]

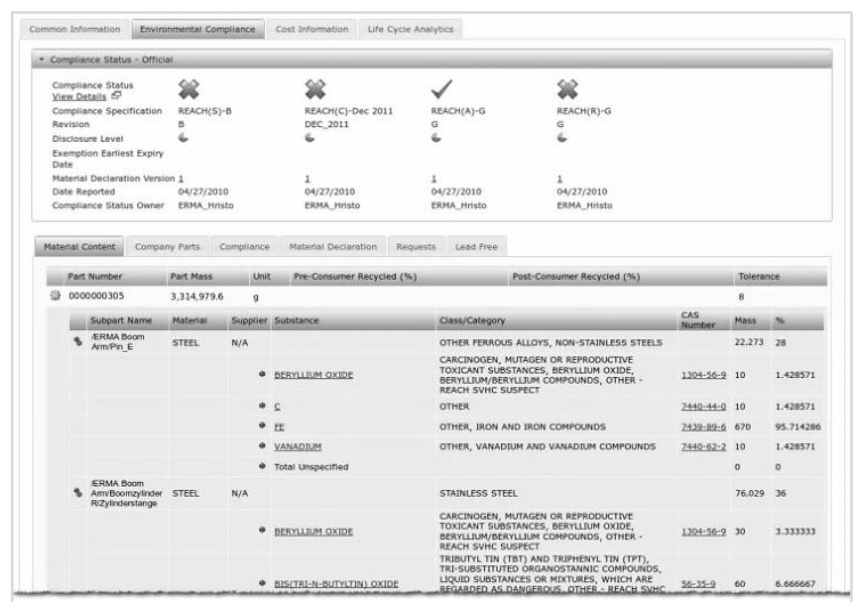

Figure 7: Environmental Compliance Dashboard of the Product Lifecycle Management Solution (adapted from [39])

The Lifecycle Cost Module (see Figure 8) enables users to easily estimate and display cost information for company or supplier parts or product systems based on different estimation model to maintain them as dynamical database. It supports cost breakdowns as well as cost confidence levels and gives an overview of the cost history of a part, assembly, product system or even chosen hydraulic and hybrid alternatives. [20] 


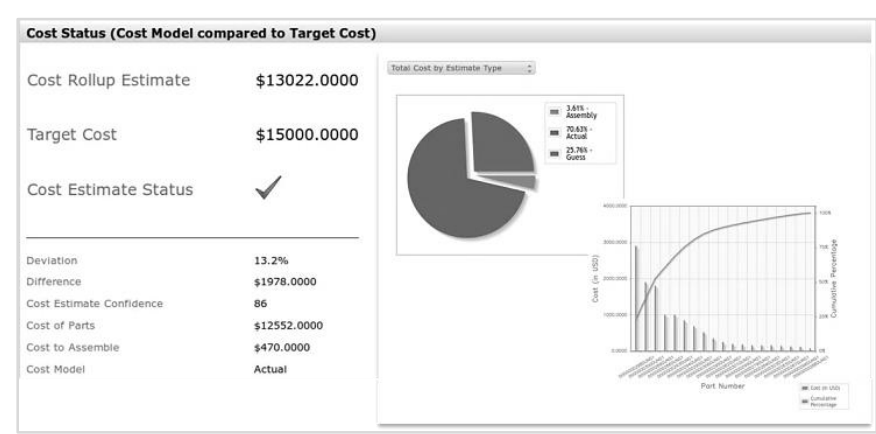

Figure 8: Life Cycle Costing Dashboard of the Product Lifecycle Management Solution (adapted from [39])

\subsection{Dependent Opportunities for Reducing Environmental Impact}

In the following, range opportunities [22] for reducing the environmental impact referring construction equipment are investigated, and are proposed as potentials for ERMA:

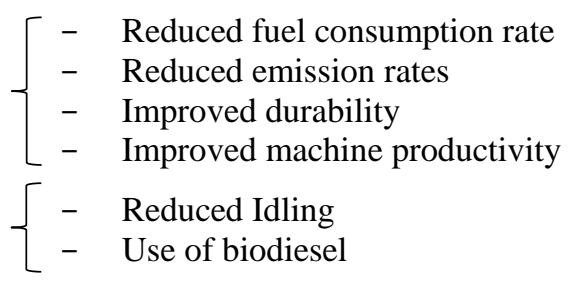

The first cluster of solutions relate to the product design while the second cluster relate to the usage behavior. Both directions are investigated for a customer related assessment.

\subsection{Integration of Technical Evaluation and Eco- Efficiency Analysis based on Product Lifecycle Management}

As consequences of technical evaluations (shown in chapter 3.1) and eco-efficiency analysis (shown in chapter 3.2) the comprehensive approach of ERMA includes integration, shown in Figure 9. Based on this, it becomes possible to analyze and optimize the current wheeled excavator focusing on new, innovative mechanical, hydraulic and electric/electronic as well as hybrid components and system solutions. The introduced Product Lifecycle Management solution is proposed as a guiding approach of the whole analysis and optimization process, with the aim of measuring multiple dimensions of the product performance in two of the three sustainability areas - ecological and economical as well as providing the data relevant for technical analysis to external software tool. Thereby existing PLM concepts will be extended by enabling the monitoring of a product life cycle already in the early phases of an engineering design process. On the technical side main topic is the analysis of hydraulic and hybrid optimizations with a digital simulation model in regard to energy loss and consumption, with consequent energy optimization of the wheeled excavator. The calculation of the energy consumption and the energy efficiency do have many versatile requirements. Here, the objective is to analyze the benefits of new technologies on the energy consumption. For the evaluation of different subsystem variants, a comprehensive system solution is required. It is necessary to evaluate the impact of different customer usage profiles on these subsystems with respect to the total energy consumption. To meet these demands, the numerical simulation model of the wheeled excavator is developed in a modular design. The model is structured in exchangeable modular sub-systems, where existing modules can be simply replaced by new ones with improved functions. In this way a direct comparison of the function, the dynamic behavior and the energy consumption of different technical solutions with respect to the used load-cycle can be accomplished.

\section{Conclusion}

The paper shows a first approach of an eco-efficiency analysis concerning economical attention of ecological parameters and technical evaluation of hydraulic and hybrid concepts for mobile working machines. New functions are developed to evaluate the technical behavior as well as the resources consumption using environmental databases. Hereby the main focus is on the structure of the system, interfaces of the functions and the implementation within a Product Lifecycle Management solution. Furthermore, a method is given, how to use a numerical simulation model for the technical evaluation of concepts. The topics are the modular structure of the simulation model and about how to deal with different customer usage profiles. The need for a linkage between the Product Lifecycle Management solution and the numerical simulation software is shown and by a comprehensive approach. The importance of lifecycle based energy and resource efficiency analysis in the sector of construction equipment is very high. A reduction of energy consumption is one of the most important innovation topics for construction equipment. In order to fulfill high energy requirements in the near future, extensive concepts, new structures and innovative technical approaches increasing the total energy efficiency of the product are needed. Therefore the importance of lifecycle based eco-efficiency analysis must be considered. Life cycle assessment (LCA) and Eco-efficiency assessment are powerful tools for achieving design for life cycle. An LCA examines all phases of the life cycle of a product system and gives a quantitative assessment of its potential environmental impact. In addition, the results of an eco-efficiency analysis help to identify priority areas for ecological improvement which are economically worthwhile. This paper presents an approach of eco-efficiency analysis as fully integrated into Product Lifecycle Management. 


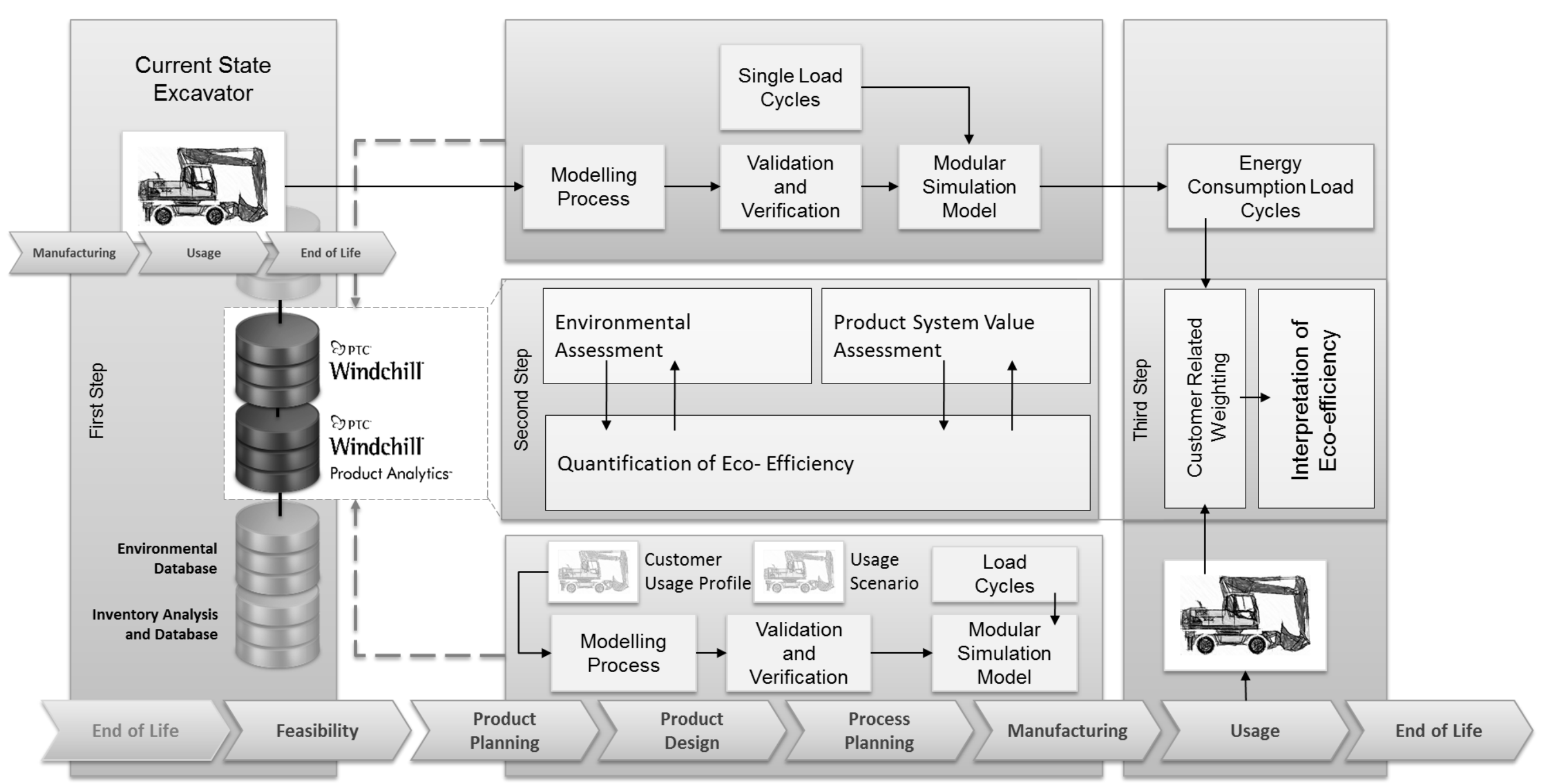

Figure 9: Integration of Technical Evaluation and Eco-Efficiency Analysis based on Product Lifecycle Management. 


\section{Acknowledgments}

The research project ERMA is funded by the Foundation for Innovation of the German state Rhineland-Palatinate. We extend our sincere thanks to all partners at the product design group at the Center of Commercial Vehicle Technology at the University of Kaiserslautern who contribute in preparing the project.

\section{References}

[1] C Holländer. Untersuchungen zur Beurteilung und Optimierung von Baggerhydrauliksystemen. FortschrittBerichte VDI Reihe 1(307). VDI, Düsseldorf, 1998.

[2] R Finzel, H Jähne, and S Helduser. Energieeffiziente Antriebssysteme mobiler Arbeitsmaschinen. Proc. of 4. Fachtagung Baumaschinentechnik. Dresden, 2009.

[3] S Pick, M Mohr, P Schaefer, C Scholler, M Eigner, S Mueller, B Sauer, and C Schindler. Lifecycle based Evaluation of new Energy- and Resource-Efficient Concepts for Mobile Working Machines. Proc. of the 2nd Commercial Vehicle Technology Symposium. Shaker, Aachen, 2012, pp. 319-328.

[4] J Blank. Sustainable Development. Lexikon Nachhaltiges Wirtschaften. Oldenbourg, München, Wien, 2001, pp. 374-385.

[5] M Eigner, $M$ von Hauff, and P Schaefer. Sustainable Product Lifecycle Management - A Lifecycle based Conception of Monitoring a Sustainable Product Development. Glocalized Solutions for Sustainability in Manufacturing. Springer, Berlin, Heidelberg, 2011, pp. 501-506.

[6] S Terzi, A Bouras, D Dutta, M Garetti, and D Kiritsis. Product Lifecycle Management - from its history to its new role. Int. J. Product Lifecycle Management, 4(4), pp. 360-389. 2010

[7] B Bras. Sustainability and product life cycle management - issues and challenges. Int. J. Product Life Cycle Management, 4(1/2/3), pp. 23-48. 2009

[8] M Eigner, and P Schaefer. Sustainable Product Lifecycle Management - A Lifecycle based Conception of Monitoring a Global Product Development in a Sustainability-Driven Century. Openness for Global Success - ProSTEP iViP Symposium 2013. Hannover, 2013, p. 70.

[9] ISO 14040. Environmental management - Life cycle assessment - Principles and framework. Beuth, Berlin, 2006.
[10]ISO 14045. Environmental management - Ecoefficiency assessment of product systems - Principles, requirements and guidelines. Beuth, Berlin, 2012.

[11] W Kloepffer. Life Cycle based methods for sustainable product development. Int. J. of Life Cycle Assessment, 8(3): pp. 157-159, Springer, Berlin, 2003.

[12]ISO 14044. Environmental management - Life cycle assessment - Requirements and guidelines. Beuth, Berlin, 2006.

[13]W Kloepffer, and B Grahl. Oekobilanz (LCA) - Ein Leitfaden für Ausbildung und Beruf. Wiley-Vch, Weinheim, 2009.

[14]E Baroulaki, and A Veshagh. Eco-Innovation - Product Design and Innovation for the Environment. Advances in Life Cycle Engineering for Sustainable Manufacturing Businesses. Springer, London, 2007.

[15]P Pickel, M Eigner. Life Cycle Assessment (LCA) and its importance for the agriculture sector. Proc. of the 23rd Annual Meeting of the Club of Bologna. Bologna, 2012.

[16] World Business Council for Sustainable Development. Eco-efficiency - Creating more value with less impact. 2000.

[17]S Feickert. Oekologisches Product Lifecycle Management - Ein Integrationskonzept der oekologischen Produktbilanzierung in betrieblichen ERPSystemen. Aachen, 2007.

[18]N Ciceri, M Garetti, and S Terzi. Product Lifecycle Management Approach for Sustainability. Proc. of the $19^{\text {th }}$ CIRP Design Conference. Cranfield, 2009, pp. 147154.

[19] K Ramani, D Ramanujan, W Bernstein, F Zhao, J Sutherland, C Handwerker, J Choi, H Kim, and D Thurston. Integrated Sustainable Life Cycle Design - A Review. J of Mechanical Design, 132. 2010

[20] M Eigner, P Schaefer, and H Apostolov. Leveraging Product Development for a Sustainable Future - Energy and Resource Efficiency in Lifecycle Analysis. Smart Product Engineering, Proc. of the $23^{\text {rd }}$ CIRP Design Conference. Springer, Berlin, Heidelberg, 2013, pp. 725-734.

[21]M Eigner, and R Stelzer. Product Lifecycle Management - Ein Leitfaden für Product Development und Life Cycle Management. 2. Ed., Springer, Berlin, Heidelberg, 2009. 
[22] M Kwak, and $\mathrm{H}$ Kim. Exploring Opportunities to Improve Life Cycle Environmental Performance of a Complex Product. Smart Product Engineering, Proc. of the $23^{\text {rd }}$ CIRP Design Conference. Springer, Berlin, Heidelberg, 2013, pp. 735-744.

[23] A Posch, and E Perl. Regionale Verwertungsnetze und industrielle Symbiose. Industrial Ecology - Mit Oekologie zukunftsorientiert wirtschaften. Elsevier, München, 2007, pp. 265-276.

[24]C Scholler, and C Schindler. Simulation der Energieverteilung innerhalb eines Load-Sensing-Ventils im Mehrverbraucherbetrieb am Beispiel eines Mobilbaggers. Proc. of the 5. Fachtagung Baumaschinentechnik 2012. Dresden, 2012, pp- 309 - 324.

[25]S Pick, S Mueller, P Bach, and U Fass. Future Wheeled Excavator - Higher Efficiency by Electrification. Proc. of the Aachener Colloquium Automobile and Engine Technolog. Aachen 2012, pp. 1577-1594.

[26] M Mohr, and B Sauer. Optimierung der Energie- und Ressourceneffizienz eines Mobilbaggers im Rahmen von ERMA. Proc. of the Antriebstechnisches Kolloquium ATK 2013. Aachen, 2013, pp. 193-220.

[27]C Scholler, C Schindler, S Pick, and S Mueller. Modularer Simulationsbaukasten zur Potenzialabschaetzung hydraulischer und hybrider Konzepte. Hybridantriebe für mobile Arbeitsmaschinen, Proc. of the 4. Fachtagung des VDMA und des Karlsruher Instituts für Technologie. KIT Scientific Publishing, Karlsruhe, 2013, pp. 61-72.

[28] VDI 2206. Design methodology for mechatronic systems. Beuth, Berlin, 2004.

[29]R Finzel, S Helduser, and D Jang. Electro-hydraulic Dual-Circuit System to improve the energy efficiency of Mobile Machines. Proc. of the 7th International Fluid Power Conference Aachen. Aachen, 2010.

[30] M Kagoshima, M Komiyama, T Nanjo, and A Tsutsui. Development of New Hybrid Excavator. Kobelco Technology Review, 2007, pp. 39-42.

[31] J Stark. Product Lifecycle Management - 21st Century Paradigm for Product Realisation. Springer, London, 2011.

[32]U Sendler. Das PLM Kompendium - Referenzbuch des Produktlebenszyklus Management. Springer, Berlin, Heidelberg, 2009.

[33]M Grieves. Product Lifecycle Management - Driving the next generation of lean thinking. New York, 2006.

[34]L Barreto, H Anderson, A Anglin, and C Tomovic. Product Lifecycle Management in support of green manufacturing - Addressing the challenges of global climate change. Int. J. of Manufacturing Technology and Management, 19(3/4), pp. 294-305. 2010.

[35]A Moeller, and A Rolf. Eco Product Lifecycle Management. Proc. of the $2^{\text {nd }}$ International Symposium on Environmentally Conscious Design and Inverse Manufacturing. Tokyo, 2001, pp. 739-744.

[36]A Abele, S Feickert, D Kuhrke, and F Clesle. Environmental Product Lifecycle Management Customizing the Enterprise Specific Manufacturing Processes. Proc. of the $13^{\text {th }}$ CIRP International Conference on Life Cycle Engineering. Leuven, 2006, pp. $651-656$

[37] A Staisch, G Peters, T Stueckl, and J Sergua. Current Trends in Product Lifecycle Management. Proc. of the $23^{\text {rd }}$ Conference on Information Systems. Geelong, 2012.

[38]H Demel. Comparison of the well-to-wheel energy efficiency of different vehicle concepts. Proc. of the $30^{\text {th }}$ International Wiener Motorensymposium. Wien, 2009.

[39] M Eigner, and $\mathrm{P}$ Schaefer. Nachhaltige Produktentwicklung im Bau von mobilen Arbeitsmaschinen mit PTC Windchill und PTC Windchill Product Analytics. PTC Live 2012, Stuttgart, 2012. 